\title{
Parvicapsula pseudobranchicola (Myxosporea) in farmed Atlantic salmon Salmo salar: tissue distribution, diagnosis and phylogeny
}

\author{
A. Nylund ${ }^{1, *}$, E. Karlsbakk ${ }^{1}$, P. A. Sæether ${ }^{2}$, C. Koren ${ }^{3}$, T. Larsen ${ }^{4}$, B. D. Nielsen ${ }^{5}$, \\ A. E. Brøderud ${ }^{6}$, C. Høstlund ${ }^{2}$, K. R. Fjellsøy ${ }^{2}$, K. Lervik ${ }^{7}$, L. Rosnes ${ }^{1}$ \\ ${ }^{1}$ Department of Biology, University of Bergen, PO Box 7800, 5020 Bergen, Norway \\ ${ }^{2}$ MarinHelse AS, Parkveien 5, 9060 Lyngseidet, Norway \\ ${ }^{3}$ Fiskehelsetjenesten i Tromsø, PO Box 2047, 9265 Tromsø, Norway \\ ${ }^{4}$ Norut NIBR Finnmark, Follums vei 33, 9510 Alta, Norway \\ ${ }^{5}$ Flatvoll, 9151 Storslett, Norway \\ ${ }^{6}$ HeMiTec, Hovedveien 2, 9151 Storslett, Norway \\ ${ }^{7}$ Grindav., 7970 Kolvereid, Norway
}

\begin{abstract}
Parvicapsula pseudobranchicola infections in farmed Atlantic salmon in Norway are associated with low-grade to significant mortalities. The parasite is found as mature spores in pseudobranchs, but has also been detected in the gills, liver and kidney. Diagnosis has relied on the detection of Parvicapsula spores, with the pseudobranch being the preferred organ. A better understanding of the epizootiology of this myxosporean is a prerequisite for appropriate management and control. Hence, early detection of infections and life cycle studies are needed. We sequenced the small subunit (ssu) rDNA (18S) from P. pseudobranchicola and developed a sensitive diagnostic PCR protocol. This allowed us to (1) identify appropriate tissues for diagnostic assays, (2) examine the intraspecific variation in ssu rDNA in the parasite's Norwegian range, (3) examine annelid potential primary hosts and (4) obtain additional ssu rDNA sequences of marine Parvicapsula species to perform a phylogenetic study. Primers were constructed targeting the ssu rDNA from P. minibicornis. With these we obtained a partial ssu sequence of the $P$. pseudobranchicola type isolate. A new set of primers (PCF3/PCR3) was constructed for diagnostic purposes. These were tested against DNA from the host and several myxozoan species infecting Norwegian salmon. The primers give a positive product of $203 \mathrm{bp}$ and pick out P. pseudobranchicola in salmonids. They also amplify the congeners $P$. unicornis and P. asymmetrica infecting unrelated fish. The PCR protocol developed showed a greater sensitivity than light microscopy. The pseudobranchs were always positive and are the recommended organ for PCR diagnostics. There was no sequence variation between geographic isolates from farmed salmon. Preliminary examinations of marine polychaetes and oligochaetes collected from farm sites with parvicapsulose problems were negative. A comparison of the sequence of the ssu rDNA from $P$. pseudobranchicola with that of other myxozoans shows that it groups closely together with $P$. unicornis and $P$. asymmetrica. The closest relative to this group is $P$. minibicornis.
\end{abstract}

KEY WORDS: Parvicapsula pseudobranchicola $\cdot$ P. unicornis $\cdot$ P. asymmetrica $\cdot \operatorname{ssu}$ rDNA $\cdot$ Molecular phylogeny $\cdot$ Diagnostic PCR

\section{INTRODUCTION}

Parvicapsula pseudobranchicola infections were first detected in 2002 in several salmon farms in northern Norway (Karlsbakk et al. 2002, Sterud et al. 2003), and the disease re-emerged in 2003 (A. Nylund pers. obs.).
Infected fish surface and appear lethargic. They are dark in colour, have eye bleedings, and some show cataracts and exophthalmia. The pseudobranchs of all affected individuals show changes, being swollen, granulomatous, haemorrhagic or partly eroded. Mortalities ranges from low-grade to significant (40\%). 
Microscopy on tissue smears from pseudobranchs of diseased fish reveal masses of trophozoites and Parvicapsula spores (Karlsbakk et al. 2002). Parvicapsula spores have also been found in other tissues like gill, liver and kidney (Sterud et al. 2003). It is believed that $P$. pseudobranchicola is the cause of the pathology and mortalities (Karlsbakk et al. 2002, Sterud et al. 2003).

Members of the genus Parvicapsula have been described as potential pathogens of both wild and farmed fish. They typically infect the kidney tubules or urinary bladder in marine fishes. In addition to $P$. pseudobranchicola, 9 species of Parvicapsula have been described (Køie 2003). An unnamed Parvicapsula species was recorded from coho salmon Oncorhynchus kisutch reared in sea water netpens in Pacific waters off Washington State, USA (Hoffman 1984). This species infected the kidneys, causing chronic proliferative nephritis and apparent significant mortality. Recently, it was discovered that the pseudobranchs are one of the primary target tissues for this species (Yasutake \& Elliot 2003) and it is likely that it may be conspecific with P. pseudobranchicola. Pacific salmonids may also be infected with $P$. minibicornis (Kent et al. 1997), which has caused or been associated with prespawn mortality among Oncorhynchus nerka (St-Hilaire et al. 2002). Trophozoites from this species are found in the glomeruli (Kent et al. 1997) and as infections progress, developmental stages are observed in the lumen of the renal tubules (Raverty et al. 2000).

The life cycle of $P$. pseudobranchicola has not been determined, but it can be assumed to involve an annelid as the main host (Kent et al. 2001, Canning \& Okamura 2004, Køie et al. 2004). It is not known if farmed Atlantic salmon acquires the parasite in fresh or salt water, nor is it known if salmon is a natural host. Lack of a sensitive diagnostic is adding to the problems surrounding this emerging salmon disease. At present, infections can only be safely diagnosed when mature spores are present in the fish tissues. Hence, the present study was undertaken to sequence the small subunit (ssu) rDNA (18S) from P. pseudobranchicola and to develop a sensitive diagnostic PCR protocol. The aims were to identify the most appropriate tissues for a diagnostic assay that could detect $P$. pseudobranchicola during the infection cycle in Atlantic salmon and to determine primers that could be used for screening of potential hosts (life cycle studies). Obtaining the ssu rDNA sequence will also allow us to examine the phylogenetic position of P. pseudobranchicola.

\section{MATERIALS AND METHODS}

Atlantic salmon Salmo salar infected with Parvicapsula pseudobranchicola were collected from 15 different sites in Norway (Table 1, Fig. 1), and include the type isolate from which the species was originally described (Karlsbakk et al. 2002). The fish stocked at these sites came from different smolt hatcheries and had been transferred to seawater sites in the late autumn or early spring. A few sites had received smolt from the same hatcheries.

Local veterinarians had diagnosed Parvicapsula pseudobranchicola in most of the farms. Salmon in a few farms were diagnosed with other diseases (infectious salmon anaemia, ISA, and salmon pancreas

Table 1. Parvicapsula pseudobranchicola from Salmo solar and Oncorhynchus mykiss. Location and date of collection (C-date) of different isolates of $P$. pseudobranchicola from salmon farms in Norway. Sea transfer: the date when the fish were transferred to netpens in seawater

\begin{tabular}{|c|c|c|c|c|c|}
\hline Location & County & Code & Sea transfer & C-date & Host \\
\hline Årøya & Troms & Т01/02 & 23 Sep 01 & 05.06 .02 & S. salar \\
\hline Årøya & Troms & T02/02 & 23 Sep 01 & 27.06 .02 & S. salar \\
\hline Store Lerresfjord & Finnmark & F03/02 & 30 Sep 01 & 12.11 .02 & S. salar \\
\hline Eidebukt & Troms & T04/02 & Sep/Oct 01 & 22.11 .02 & S. salar \\
\hline Skjervøy & Troms & T05/02 & - & 16.12.02 & S. salar \\
\hline Sjursnes & Troms & $\mathrm{T} 10 / 03$ & 3 Sep 01 & 20.01 .03 & S. salar \\
\hline Svensby & Troms & $\mathrm{T} 11 / 03$ & Jun/Jul 01 & 20.01 .03 & S. salar \\
\hline Årøya & Troms & $\mathrm{T} 12 / 03$ & - & 19.03 .03 & S. salar \\
\hline Hundbergan/Langfjorden & Finnmark & F13/03 & Aug/Oct 01 & 27.03 .03 & S. salar \\
\hline Uløy & Troms & $\mathrm{T} 14 / 03$ & - & 28.04 .03 & S. salar \\
\hline Osholmane, Hitra & Sør-Trønderlag & ST15/03 & - & 16.05 .03 & S. salar \\
\hline Nærøy & Nord-Trønderlag & NT16/03 & 8 Jun 02 & 03.06 .03 & S. salar \\
\hline Nærøy & Nord-Trønderlag & NT17/03 & 9 Aug 02 & 30.06 .03 & O. mykiss \\
\hline Angstauren & Troms & $\mathrm{T} 19 / 03$ & 5 May 03 & 01.09 .03 & S. salar \\
\hline Sandnes & Troms & T20/03 & Apr/May 03 & 04.09 .03 & S. salar \\
\hline$\varnothing \mathrm{ksfjord}$ & Finnmark & $\mathrm{F} 21 / 03$ & May 03 & 05.09 .03 & S. salar \\
\hline Kåvika & Troms & $\mathrm{T} 22 / 03$ & Sep/Oct 03 & 01.10 .03 & O. mykiss \\
\hline Strandmo & Troms & $\mathrm{T} 23 / 03$ & May/Jul 03 & 29.09 .03 & S. salar \\
\hline
\end{tabular}




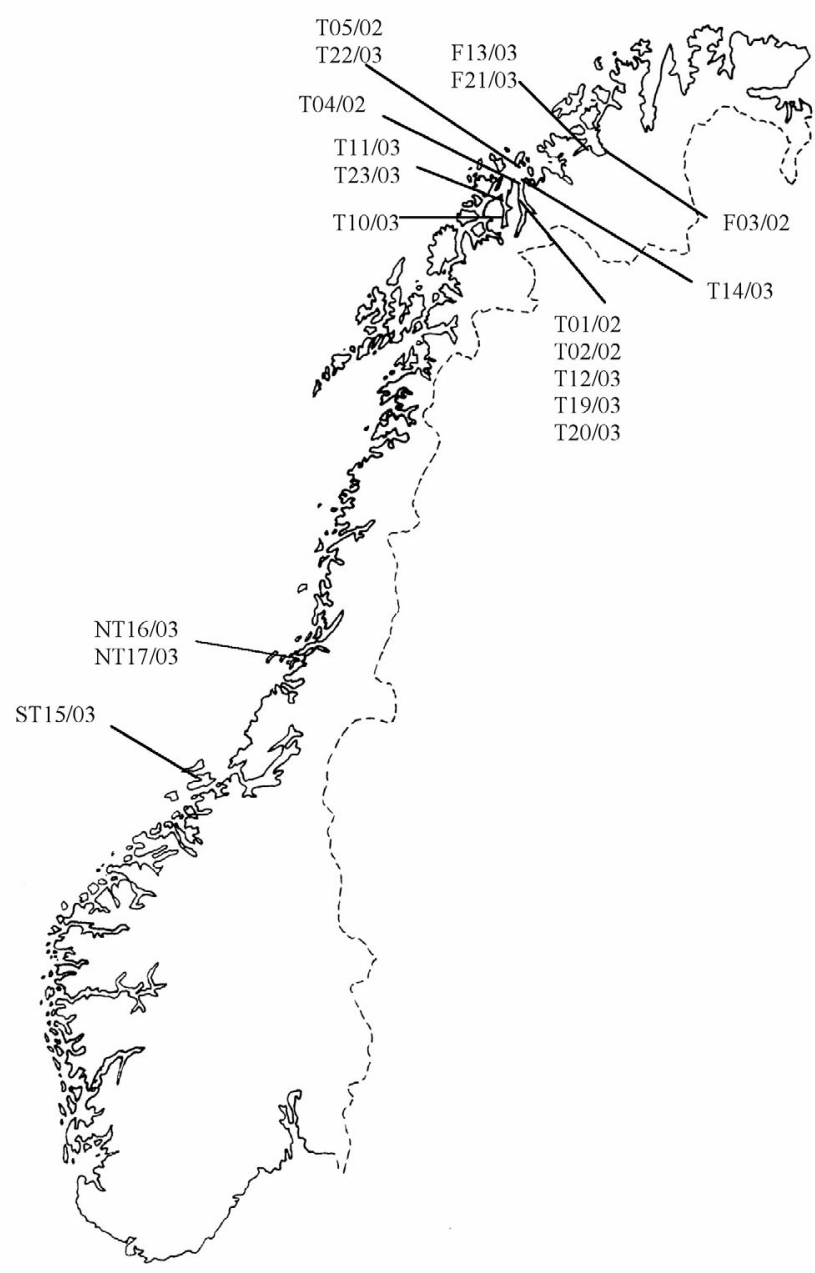

Fig. 1. Location of the different isolates of Parvicapsula pseudoÏbranchicola in Norway

disease, SPD) and the fish were sent to us for confirmation of the respective diagnosis. Since these farms were located in areas with parvicapsulosis, the salmon were also screened for presence of this parasite.
The pseudobranch tissues from all the fish included in this study were first checked by light microscopy for Parvicapsula pseudobranchicola. Tissues for DNA extraction were taken from pseudobranchs, gills (1st gill arch), liver, mid-kidney, spleen, eye (choroidea), hindgut wall and heart (ventricle). DNA was extracted from the collected tissues of (1) infected hosts, (2) hosts without presence of spores, and (3) hosts that were from a risk area, using the DNeasy protocol for animal tissues (Qiagen). The DNA was eluted in $50 \mu \mathrm{l} \mathrm{AE}$ buffer supplied with the Qiagen-kit and stored at $-20^{\circ} \mathrm{C}$ before use in a PCR.

PCR primers were constructed based on ssu rDNA sequences from Parvicapsula minibicornis (Accession no. AF201375, Kent et al. 2000), and in combination with a general ssu PCR primer, Ecf, they were used to pick out the first part of the ssu from P. pseudobranchicola (Table 2). In addition, PCR primers and diagnostic primers for Parvicapsula spp. were made based on the ssu sequence from P. pseudobranchicola (Accession no. AY308481). The primers were targeting conserved areas of the ssu rDNA and at the same time avoiding areas that showed close similarities to salmon ssu rDNA. An overview of the primers is given in Table 2. The PCR amplifications were performed in a total volume of $50 \mu \mathrm{l}$ using $2 \mu \mathrm{l}$ of template DNA. The reaction mixture consisted of $5 \mu \mathrm{l} 10 \times$ PCR buffer, $5 \mu \mathrm{l}$ $10 \mathrm{mM}$ dNTP, $1 \mu \mathrm{l}(10 \mathrm{mM})$ of the reverse and forward primer, $2 \mathrm{U}$ of thermostable DNA polymerase (Quiagen), and $36 \mu \mathrm{ldH_{2 }} \mathrm{O}$. The PCR conditions were as follows: after an initial 5 min denaturation step at $95^{\circ} \mathrm{C}$, samples were taken through 35 amplification cycles, each consisting of a $30 \mathrm{~s}$ denaturation step at $94^{\circ} \mathrm{C}$, a $30 \mathrm{~s}$ primer annealing step at a temperature dependent on the primer combination used, and a $1 \mathrm{~min}$ and $30 \mathrm{~s}$ extension step at $72^{\circ} \mathrm{C}$. A prolonged extension step of $10 \mathrm{~min}$ at $72^{\circ} \mathrm{C}$ completed each reaction.

The diagnostic primer set, PCF3/PCR3, was tested against genomic DNA from salmon and from a selec-

Table 2. Primer sequences and locations in relation to a partial ssu rDNA sequence of Parvicapsula pseudobranchicola (Accession no. AY308481)

\begin{tabular}{|c|c|c|c|}
\hline Primer & Sequence & Location & Source \\
\hline Ecf & 5'-GTT CGA TTC CGA GAG GGA GC-3' & Outside & \\
\hline PCF1 & 5'-AAA CTC AAG TTT TCG GGT TAC GG-3' & $1132-1154$ & \\
\hline PCF3 & 5'-TTG ACG GAA GGG CAC CAC AAG G-3' & $1190-1211$ & \\
\hline PCF4 & 5'-CTG TGT AAG TTC TTT CCG ACA TGG-3' & $4-27$ & \\
\hline PCF7 & 5'-SGA WAG TTT GAT CGA ATT TCT GCC-3' & $251-274$ & Precent ctudy \\
\hline PCR1 & 5'-TCA ATG CTG AAG CCA TAG GC-3' & $470-451$ & Present study \\
\hline PCR2 & 5'-CGG GCG GTG TGT ACA AAG GGC-3' & Outside & \\
\hline PCR3 & 5'-AAC TAG ACA CCG TGG TCT CGC TCG-3' & $1392-1369$ & \\
\hline PCR4 & 5'-CAG CAC TGA GTA AAC CCA ATA CTG-3' & $150-127$ & \\
\hline PCR5 & 5'-AAC ACG CAG TTG GTG ACT CG-3' & $1656-1637$ & \\
\hline Myxgen4r & 5'-ACC TGT TAT TGC CAC GCT-3' & $1479-1462$ & Kent et al. (2000) \\
\hline
\end{tabular}


tion of other myxozoan parasites (Parvicapsula unicornis and Leptotheca elongata from Merluccius merluccius, Parvicapsula asymmetrica from Cyclopterus lumpus, Sphaerospora truttae from Salmo trutta, Chloromyxum truttae and Myxidium truttae from Salvelinus alpinus) to see if they would give any products (i.e. if they targeted DNA from any organisms other than Parvicapsula pseudobranchicola). The diagnostic primers were also tested by computer analysis on sequences from other myxozoan species. The hybridisation sites for PCF3 and PCR3 gave no higher match than 95.5 and $95.8 \%$, respectively. The computer analysis of $P$. minibicornis gave the highest match. However, the diagnostic primers do give a $100 \%$ match with the ssu sequence of $P$. unicornis from M. merluccius and P. asymmetrica from C. lumpus, and resulting products. The optimum conditions for the diagnostic PCR were as follows: An initial denaturation step at $95^{\circ} \mathrm{C}$ for $5 \mathrm{~min}$ followed by 35 amplification cycles, each consisting of a $30 \mathrm{~s}$ denaturation step at $94^{\circ} \mathrm{C}$ and a $45 \mathrm{~s}$. annealing and extension step at $72^{\circ} \mathrm{C}$. A prolonged extension step of $10 \mathrm{~min}$ at $72^{\circ} \mathrm{C}$ completed jthe reaction. The PCR products were analysed by electrophoresis on a $1 \%$ agarose gel.

The PCR products were purified on Qia-quick PCR Purification columns (Qiagen) and then sequenced using the BigDye Terminator Sequencing kit. The sequencing was done using the amplification primers (upstream and downstream primers) described above.

The diagnostic primers were also used to screen other fish species for possible presence of Parvicapsula pseudobranchicola. Several tissues from rainbow trout Oncorhynchus mykiss that were kept in 2 farms (NT16/03 and T22/03), where the salmon in the neighbouring netpens were positive for $P$. pseudobranchicola, were screened for presence of this parasite. In addition, pseudobranchs from wild fish (cod Gadus morhua, whiting Merlangius merlangius, saith Pollachius virens, wolffish Anarhichas lupus, flounder Platichthys flesus) collected by gillnet close to infected farms were also screened for presence of $P$. pseudobranchicola.

The sequence data were assembled with the help of Vector NTI software (InforMax) and GenBank searches were done with BLAST (2.0). The vector NTI Suite software package was used for multiple alignments of the partial sequences. The sequences of Parvicapsula pseudobranchicola (AY308481), P. unicornis (AY584190) and P. asymmetrica (AY584191) were aligned with homologous ssu rDNA sequences from a selected number of myxozoans already available on the EMBL nucleotide database: Ceratomyxa sparusaurati AF411471, C. labracis AF411472, C. shasta AF001579, Ellipsomyxa gobii AY505127 and AY505127, Enteromyxum leei AF411334, En- teromyxum scophthalmi AF411335, Henneguya exilis AF021881, H. ictaluri AF195510, H. zschokkei AF378344, K. amamiensis AY152748, Kudoa crumena AF378347, Kudoa minithyrsites AY152749, K. thyrsites AY078430, Myxidium lieberkuehni X76638, M. truttae AF201374, Myxobolus bibullatus AF378336, Myxobolus cerebralis MCU096492, Myxobolus pendula AF378340, Parvicapsula minibicornis AF201375, Pentacapsula neurophila AY172511, Sphaerospora molnari AF378345, Sinuolinea sp. AF378346, Sphaerospora oncorhynchi AF201373, Sphaerospora trutta AJ416572 and Zschokkella mugilis AF411336. Sequences from Buddenbrockia plumatellae (AY074914) and Tetracapsuloides bryosalmonae (AJ133563) were used as outgroups. To perform pairwise comparisons between the different species ssu rDNA, the multiple sequence alignment editor GeneDoc (available at www.psc.edu/biomed/genedoc) was used. In addition to software analysis of the sequences, the polymorphic region of the ssu was manually aligned and compared for all species. Due to extremely high rates of insertions and deletions in some regions, analyses were conducted without these hypervariable sites so as to secure comparison of homologous areas of the rDNA.

Phylogenetic analyses of the data sets were performed using PAUP* 4.0 version (Swofford 1998) and TREE-PUZZLE 5.0 (available at http://www.tree-puzzle.de). Phylogenetic trees were drawn using TreeView (Page 1996).

\section{RESULTS}

The ssu rDNA of Parvicapsula pseudobranchicola was sequenced (Accession no. AY308481) from 8 different isolates collected from localities in 4 different counties (Finnmark, Troms, Nord Trønderlag and Sør Trønderlag) along the Norwegian coast. Six samples were taken from farmed Atlantic salmon Salmo salar and 2 samples (NT17/03 and T22/03) from rainbow trout Oncorhynchus mykiss that were kept in farms together with salmon infected with P. pseudobranchicola. No sequence variation was observed between the isolates from the different localities. BLAST searches using the obtained $P$. pseudobranchicola sequence confirmed that the most similar sequence to this sequence, in the GenBank, is the ssu rDNA sequence from $P$. minibicornis, phylum Myxozoa (Kent et al. 1998). A comparison of $1663 \mathrm{bp}$ from $P$. pseudobranchicola with the sequence from P. minibicornis shows a $77 \%$ similarity. The difference is due largely to a long insertion in $P$. minibicornis (or a deletion in $P$. pseudobranchicola). Referring to the sequence of $P$. minibicornins (AF201375) the insert stretches from Position 1469 to Position 1582. However, the ssu rDNA sequence from the 2 other species, $P$. unicornis from 
Table 3. Sequence similarity (\% upper half) of the ssu rDNA from Parvicapsula spp. and a related species (Zschokkella mugilis). Number of nucleotides compared (the lower half of the table)

\begin{tabular}{|lccccc|}
\hline Species & P. pseudobranchicola & P. asymmetrica & P. unicornis & P. minibicornis & Z. mugilis \\
\hline P. pseudobranchicola & & 94 & 89 & 77 & 76 \\
P. asymmetrica & $1587 / 1592$ & & 90 & 77 & 77 \\
P. unicornis & $1567 / 1599$ & $1560 / 1587$ & & 77 \\
P. minibicornis & $1786 / 1663$ & $1711 / 1587$ & $1731 / 1580$ & $1591 / 1831$ \\
Z. mugilis & $1546 / 1663$ & $1474 / 1587$ & $1495 / 1580$ & 74 \\
\hline
\end{tabular}

Merluccius merluccius (Accession no. AY584190) and $P$. asymmetrica from Cyclopterus lumpus (Accession no. AY584191), showed a higher similarity to $P$. pseudobranchicola (Table 3) than P. minibicornis. The sequence similarities between $P$. pseudobranchicola and Tetracapsuloides bryosalmonae, Myxobolus cerebralis (MCU96493), Ceratomyxa labrachis (AF411472) and Kudoa spp. (AF378347, AY078430, AY152747, AY152748, AY152749) are 65, 66, 72 and 73 to $74 \%$, respectively.

The ssu rDNA regions of the Parvicapsula pseudobranchicola, $P$. unicornis and $P$. asymmetrica, were aligned with known homologous ssu rDNA sequences from several myxozoan species belonging to a representative range of genera. A phylogenetic tree was constructed from the genetic data obtained from this comparison of homologous rDNA (Fig. 2). High bootstrap values of $100 \%$ support a close relationship between P. pseudobranchicola, P. unicornis and P. asymmetrica. P. minibicornis seem to constitute a sister group to the other 3 Parvicapsula species (support value $99 \%$ ). The Parvicapsula species group together (support value $=98$ ) with marine coelozoic species and the histozoic Kudoa and Enteromyxum species.

Salmon from most of the farms included in this study had been diagnosed with parvicapsulosis before they were sent to our laboratory. When they arrived they were also screened for the presence of other parasites, but no other parasites that could explain the observed pathology were found. However, the salmon from a few of the selected farms were positive for infectious pancreatic necrosis virus (IPNV), infectious salmon anaemia virus (ISAV) and salmonid myopathy alphavirus (SMAV). These viruses may have influenced the observed mortality in these farms.

The number of individuals that were found positive for Parvicapsula after screening squash preparations of pseudobranchs compared to the number of positive fish after PCR diagnostic on the same tissue is given in Table 4. On most farms all individuals were positive for P. pseudobranchicola, but spores were found in only a few farms using the microscopic method. The difference between these 2 methods varies with the time of collection. When mature spores are pre- sent in the fish, i.e. late in the parasite life cycle within the host, the results of microscopy and PCR are the same (Table 4).

Salmon diagnosed with other diseases (infectious salmon anaemia and salmon pancreas disease) from

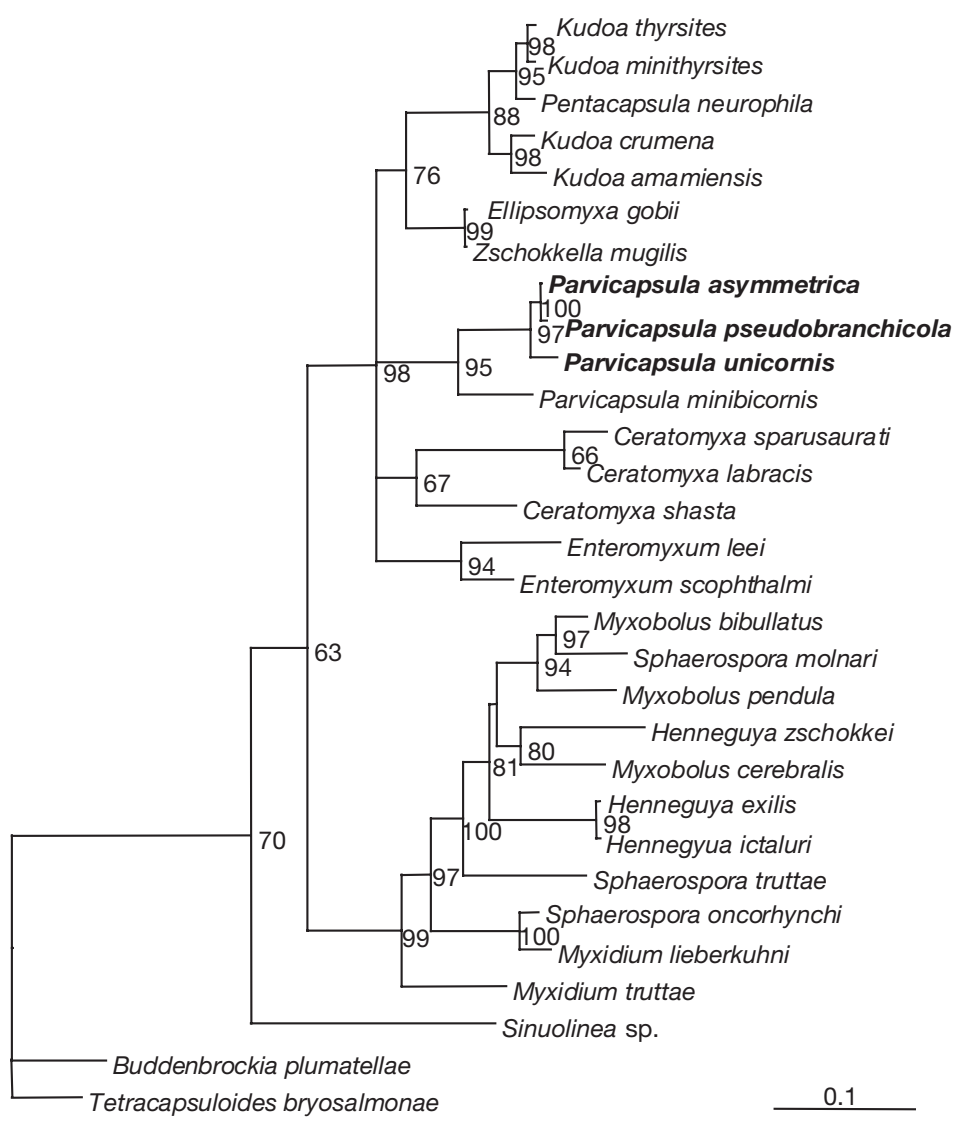

Fig. 2. Phylogenetic position of Parvicapsula pseudobranchicola in relation to a selection of Myxozoa. P. pseudbranchicola groups closely together with the type species $P$. asymmetrica from Cyclopterus lumpus. The relationship is presented as a maximum likelihood tree based on alignment of ssu rDNAs. Branch lengths represent relative phylogenetic distances according to maximum likelihood estimates. Quartet puzzling (QP) support values $>70$ can in principle be trusted, which means that the phylogeny is only partly resolved. The scale bar shows the number of nucleotide substitutions as a proportion of branch length 
Table 4. Pseudobranch samples from farmed Salmo salar examined for presence of Parvicapsula pseudobranchicola using light microscopy and PCR as diagnostic tools. The location is given by the isolate code (see Table 1). The date of collection is given in the second column. $\mathrm{N}$ : number of individuals screened, Micr.: number of positive individuals after microscopy (presence of spores), PCR: number of positive individuals after PCR diagnostics

\begin{tabular}{|lcrrr|}
\hline $\begin{array}{l}\text { Sample } \\
\text { location }\end{array}$ & Date & N & Micr. & PCR \\
\hline T01/02 & 5 Jun 02 & 11 & 11 & 11 \\
F03/02 & 12 Nov 02 & 5 & 0 & 3 \\
T10/03 & 20 Jan 03 & 10 & 9 & 10 \\
T12/03 & 19 Mar 03 & 11 & 0 & 11 \\
ST15/03 & 16 May 03 & 48 & 21 & 42 \\
T19/03 & 1 Sep 03 & 7 & 7 & 7 \\
T20/03 & 4 Sep 03 & 21 & 0 & 21 \\
F21/03 & 5 Sep 03 & 12 & 0 & 12 \\
T22/03 & 1 Oct 03 & 7 & 0 & 3 \\
\hline
\end{tabular}

farms in areas where parvicapsulosis occurs were screened (microscope) for presence of spores from Parvicapsula pseudobranchicola, but no spores were observed. However, use of the diagnostic PCR (primer set PCF3/PCR3) showed that P. pseudobranchicola was also present in the fish suffering from ISA. The products were sequenced to confirm that it was $P$. pseudobranchicola that we had detected.

None of the samples from wild fish were positive for Parvicapsula pseudobranchicola using the diagnostic primers. However, rainbow trout collected from a salmon farm where P. pseudobranchicola was present on salmon, were also positive. The trout did not show any clinical signs of disease or presence of mature spores, despite the presence of mature spores in salmon in neighbouring netpens.

The tissue distribution of Parvicapsula pseudobranchicola in infected salmon from 3 different farms was checked with the help of the diagnostic PCR (primer set PCF3/PCR3). The 3 collection sites are close to each other in northern Norway (Troms/Finnmark) and the dates of collection are 20 January, 19 March and 27 March 2003 (Table 5). In the sample from January (T10/03) the parasite was present in all tissues, including blood, from all salmon studied. In
March (T12/03 and F13/03) the situation was different and the pseudobranchs were the most frequently positive tissue. In the March sample (T12/03), where the blood was negative, the gills and heart were nearly as frequently positive as the pseudobranchs. The lowest prevalences of $P$. pseudobranchicola were found in the March samples of blood and spleen from farms T12/03 and F13/03, respectively.

\section{DISCUSSION}

The 18S rDNA sequence (Accession no. AY308481) provided for Parvicapsula pseudobranchicola makes it possible to study its taxonomic placement within the phylum Myxozoa. The sequence was compared with a selection of other myxosporean sequences selected from a BLAST search and available in the GenBank. The sequences from $P$. unicornis and $P$. asymmetrica were also included in the phylogenetic analysis. The malacosporeans Tetracapsuloides bryosalmonae and Buddenbrockia plumatellae were used as an outgroup since previous phylogenetic analyses of the phylum Myxozoa have demonstrated that they represent an early branch of the Myxozoa (Kent et al. 2001). In this study P. pseudobranchicola groups closely together with $P$. unicornis and $P$. asymmetrica, the type species of Parvicapsula. P. minibicornis seem to constitute a sister group to the other Parvicapsula species. It is possible, based on morphology and 18S rDNA, that the genus Parvicapsula should be divided into 2 separate genera. However, before such a problem can be addressed, more species within this genus need to be sequenced. The genetic difference between $P$. minibicornis and the other 3 Parvicapsula species included in this study is mainly due to a long insertion in the sequence of the former (or a deletion in the latter).

The diagnosis of Parvicapsula pseudobranchicola, the causative agent of parvicapsulosis in Atlantic salmon Salmo salar, currently relies on isolation and then identification of spores in squash preparations or sections from the pseudobranchs (Karlsbakk et al. 2002, Sterud et al. 2003). Unfortunately, this diagnostic procedure is inadequate in detecting all stages of infection in salmon and is of no help in the search for the

Table 5. Salmo salar. Tissue distribution of P. pseudobranchicola revealed by PCR diagnostics. The columns give the number of positive tissues compared to the number of tissues tested. Code: Location of the isolates (see Table 1), pseudo: pseudobranch

\begin{tabular}{|lrrrrrrrrr}
\hline Code & Pseudo & Gill & Kidney & Liver & Heart & Blood & Spleen & Eye & Gut \\
\hline T10/03 & $10 / 10$ & $10 / 10$ & $10 / 10$ & $10 / 10$ & $10 / 10$ & $10 / 10$ & $10 / 10$ & $10 / 10$ & $10 / 10$ \\
T12/03 & $11 / 11$ & $8 / 11$ & $5 / 11$ & $6 / 11$ & $10 / 11$ & $0 / 11$ & $5 / 11$ & $4 / 11$ \\
F13/03 & $14 / 24$ & $9 / 24$ & $4 / 24$ & $4 / 24$ & $5 / 24$ & $6 / 24$ & $1 / 24$ & $4 / 24$ & $4 / 24$ \\
\hline
\end{tabular}


likely main host. These concerns led us to develop a diagnostic PCR method for the detection of P. pseudobranchicola. The genomic DNA (ssu rDNA) represents an invariable target for detection of a given species as opposed to the radically different morphological forms in the development of actinosporeans and myxosporeans. The 18S rRNA gene was sequenced from 8 different isolates collected in farms producing salmonids (salmon and rainbow trout) from 4 different counties in Norway, and no variation in the sequences was found. This means that diagnostic primers targed against this sequence should be able to pick out this parasite species when present. It is noteworthy that the lack of variation in $P$. pseudobranchicola SSU is compatible with an introduction hypothesis: the possibility that this myxosporidian was recently introduced to Norwegian waters.

The diagnostic primers designed (PCF3 and PCR3) target regions of the rRNA gene that are slightly different from the same regions in Parvicapsula minibicornis and the host (S. salar), but identical to that of $P$. unicornis and $P$. asymmetrica. Testing the primers by computer analyses on sequences from other myxozoan species found no sites for hybridisation with more than $95 \%$ match. This was confirmed by performing PCR tests on genomic DNA isolated from Salmo salar, Oncorhynchus mykiss and myxozoan species (similar tests on a selection of oligochaetes and polychaetes have also been negative). Diagnostic PCR on tissues from Gadus morhua, Merlangius merlangius, Pollachius virens, Anarhichas lupus, Platichthys flesus and $O$. mykiss also gave negative results, i.e. no match with these fish species' genome.

The sensitivity of the diagnostic primers was not tested, but comparison with microscopy showed a higher sensitivity, since the latter can only be safely used when mature spores are present (Table 3). The PCR method is more time-consuming (about $4 \mathrm{~h}$ including DNA extraction, PCR and gel electrophoresis) than microscope examination of squash preparations. However, the limitations on the use of microscopy make the PCR the best choice for a confirmative diagnostic of the disease, detection of infection before development of disease, screening of possible hosts, and for life cycle studies.

The PCR assay provides a sensitive approach for detection of the earliest developmental stages pres-ent in farmed salmon (Table 4). PCR positive blood was found in several individuals. This may be a result of circulating spores, but more likely suggests that Parvicapsula pseudobranchicola has blood stages in the salmon. Such stages have been documented in several myxozoan groups, like Sphaerospora spp. (Lom et al. 1985) and Kudoa (Moran et al. 1999a,b), and are recognised as a phase of parasite proliferation prior to sporogeny in the typical site. This means that if the infection pressure at a farm site is limited to a short period (a few weeks or a month) during liberation of actinospores from the main host, salmon at that site can be screened shortly afterwards for presence of the parasite. The method can also be used, with high reliability, on biopsies from the gills (and blood) of salmon, which means that salmon can be screened without first being killed. In the future this could be a valuable method for risk analyses of salmon farms in areas where the parasite is present if there is a correlation between prevalence of the parasite and development of disease and number of losses. Since it is unlikely that any treatment will be developed for parvicapsulosis in the near future, the main use of this method will be for the farmer to decide if further investment in feeding is better than culling the infected populations.

The greatest asset of this PCR test is its ability to detect all possible stages of the parasite, including both actinosporean and myxosporean stages. These stages can be found in hosts and some also in water and possibly in sediments, faeces of fish-eating animals, and inanimate objects that may serve to transport infective stages (cf. Andree et al. 1998). A major use of this method will be to identify invertebrate hosts in the parasite life cycle (e.g. Køie et al. 2004), which could be of vital importance for future management of the disease. However, the method may also be used to check for presence of actinosporeans in seawater at farming sites and in wellboats used for transportation of smolt. Hence, it is a valuable tool for risk analysis and disease management. Since the primers will also detect Parvicapsula unicornis and $P$. asymmetrica, the PCR products have to be sequenced when the assay is used on other hosts (primary and intermediate) and environmental samples. It cannot be excluded that the primers, PCR2/PCF3, may detect other members of the genus Parvicapsula: hence, when used on samples other than salmon tissue, the products should be sequenced.

\section{LITERATURE CITED}

Andree KB, MacConnel E, Hedrick RP (1998) A nested polymerase chain reaction for the detection of genomic DNA of Myxobolus cerebralis in rainbow Oncorhynchus mykiss. Dis Aquat Org 34:145-154

Canning EU, Okamura B (2004) Biodiversity and evolution of the Myxozoa. Adv Parasitol 56:43-131

Hoffman GL (1984) Two fish pathogens, Parvicapsula sp. and Mitraspora cyprini Myxosporea, new to North America. Symp Biol Hung 23:127-135

Karlsbakk E, Sæther PA, Høstlund C, Fjellsøy KR, Nylund A (2002). Parvicapsula pseudobranchicola n.sp. (Myxozoa), a myxosporidean infecting the pseudobranch of cultured Atlantic salmon (Salmo salar) in Norway. Bull Eur Ass Fish Pathol 22:381-387 
Kent ML, Whitaker DJ, Dawe SC (1997) Parvicapsula minibicornis n. sp. (Myxozoa, Myxosporea) from the kidney of Sockeye salmon (Oncorhynchus nerka) from British Columbia, Canada. J Parasitol 83:1153-1156

Kent ML, Khattra J, Hervio DML, Devlin RH (1998) Ribosomal DNA sequence analysis of isolates of the PKX Myxosoporean and their releationship to members of the genus Sphaerospora. J Aquat Anim Health 10:12-21

Kent ML, Khattra J, Hedrick RP, Devlin RH (2000) Tetracapsula renicola n. sp (Myxozoa: Saccosporidae); the PKX myxozoan - the cause of proliferative kidney disease of salmonid fishes. J Parasitol 86:103-111

Kent ML, Andree KB, Bartholomew JL, El-Matbouli M and 12 others (2001) Recent advances in our knowledge of the Myxozoa. J Eukaryot Microbiol 48:395-413

Køie M (2003) Parvicapsula spinachiae n.sp. (Myxozoa, Parvicapsulidae) in Spinachia spinachia (L.) (Teleosei, Gasterosteidae) from Denmark. Parasitol Res 90: 445-448

Køie M, Whipps CM, Kent ML (2004) Ellipsomyxa gobii (Myxozoa: Ceratomyxidae) in the common goby Pomatoschistus microps (Teleostei: Gobiidae) uses Nereis spp. (Annelida : Polychaeta) as invertebrate hosts. Folia Parasitol 51:14-18

Lom J, Pavlásková M, Dyková I (1985) Notes on kidneyinfecting species of the genus Sphaerospora Thélohan (Myxosporea), including a new species $S$. gobionis sp. nov., and on myxosporean life cycle stages in the blood of some freshwater fish. J Fish Dis 8:221-232

Moran JDW, Margolis L, Webster JM, Kent ML (1999a)

Editorial responsibility: Otto Kinne (Managing Editor), Oldendorf/Luhe, Germany
Development of Kudoa thyrsites (Myxozoa: Myxosporea) in netpen-reared Atlantic salmon determined by light microscopy and a polymerase chain reaction test. Dis Aquat Org 37:185-193

Moran JDW, Whitaker DJ, Kent ML (1999b) Natural and laboratory transmission of the marine myxozoan parasite Kudoa thyrsites to Atlantic salmon. J Aquat Anim Health 11:110-115

Page RDM. (1996) TREEVIEW: an application to display phylogenetic trees on personal computers. Comput Appl Biosci 12:357-358

Raverty S, Kieser D, Bagshaw J, St-Hilaire S (2000) Renal infestation with Parvicapsula minibicornis in wild sockeye salmon from the Harrison and Adams rivers in British Columbia. Can Vet J 41:317-318

Sterud E, Simolin P, Kvellestad A (2003) Infection by Parvicapsula sp. (Myxozoa) is associated with mortality in seacaged Atlantic salmon Salmo salar in northern Norway. Dis Aquat Org 54:259-263

St-Hilaire S, Boichuk M, Barnes D, Higgins and 5 others (2002) Epizootiology of Parvicapsula minibicornis in Frasier river sockeye salmon, Oncorhynchus nerka (Walbaum). J Fish Dis 25:107-120

Swofford DL (1998) Phylogenetic analysis using parsimony and other methods, version 4.0. Sinauer Associates, Sunderland, MA

Yasutake WT, Elliot DG (2003). Epizootiology and histopathology of Parvicapsula sp. in coho salmon Oncorhynchus kisutch. Dis Aquat Org 56:215-221

Submitted: June 30, 2004; Accepted: October 10, 2004 Proofs received from author(s): February 14, 2005 